\title{
Velocity control in Parkinson's disease: a quantitative analysis of isochrony in scribbling movements
}

Paolo Viviani • Pierre R. Burkhard •

Sabina Catalano Chiuvé · Corrado Corradi-Dell'Acqua •

Philippe Vindras

Published online: 13 February 2009

(C) Springer-Verlag 2009

Erratum to: Exp Brain Res

DOI 10.1007/s00221-008-1695-z

The name of the author Corrado Corradi-Dell' Acqua is not published correctly in the author affiliations in the online version.

The name should appear as C. Corradi-Dell'Acqua instead of C. C. dell' Acqua.

The online version of the original article can be found under doi:10.1007/s00221-008-1695-z.

P. Viviani $(\bowtie)$

Faculty of Psychology and Educational Sciences,

University of Geneva, 40, Boulevard du Pont d'Arve 1205,

Geneva, Switzerland

e-mail: viviani@pse.unige.ch

P. R. Burkhard

Department of Neurology, Faculty of Medicine,

Geneva University Hospitals, Geneva, Switzerland

S. C. Chiuvé

Department of Neurology, Neuropsychology Unit,

Geneva University Hospitals, Geneva, Switzerland

C. Corradi-Dell'Acqua

Cognitive Neuroscience Sector, SISSA, Trieste, Italy

P. Vindras

Laboratory of Neurophysiology of Perception and Movement,

Institute of Cognitive Science, CNRS UMR 5229 Bron, France 